\title{
Propuesta de un Informe de Capital Intelectual para las instituciones de educación superior españolas
}

\author{
YOLANDA RAMíREZ CóRCOLES ${ }^{\text {a }}$, Jesús F. SANTOS PEÑALVER ${ }^{\text {a }}$ \\ a Universidad de Castilla-La Mancha, Facultad CC.EE., Plaza de la Universidad, $n^{\circ}$ 1, 02071 \\ Albacete, España.E-mail: Yolanda.Ramirez@uclm.es, Jesus.Santos@uclm.es
}

\begin{abstract}
RESUMEN
El capital intelectual llega a ser un tema fundamental en las universidades debido, principalmente, al hecho de que el conocimiento es el principal output e input en estas instituciones, lo cual nos lleva a plantear la necesidad de que las universidades españolas presenten información sobre su capital intelectual. Los resultados obtenidos en este trabajo suponen un importante punto de partida para que las instituciones de educación superior puedan identificar qué información sobre capital intelectual es la más demandada por sus stakeholders y en base a ello elaborar un informe de capital intelectual. De este modo, y como conclusión lógica del estudio realizado, se presenta una propuesta de informe de capital intelectual para las universidades españolas.
\end{abstract}

Palabras claves: Capital intelectual, informe, universidades, España.

\section{Proposal of Intellectual Capital Report to Spanish Higher Education Institutions}

\begin{abstract}
Intellectual capital approach becomes critical at universities, mainly due to the fact that knowledge is the main output as well as input in these institutions. This prompted us to raise the need to disclose information on their intellectual capital. Our results represent a starting point for higher education institutions to identify what is the most requested information about intellectual capital, and therefore to develop an intellectual capital report. The logical conclusion of our study is the presentation of a proposal of intellectual capital report for Spanish universities.
\end{abstract}

Keywords: Intellectual Capital, Report, Universities, Spain.

Clasificación JEL: I23, M14, M41

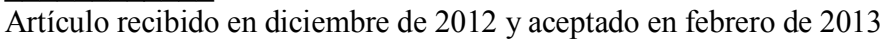

Artículo disponible en versión electrónica en la página www.revista-eea.net, ref. ə-31203 


\section{INTRODUCCIÓN}

En el actual contexto de la Sociedad del Conocimiento el sector de la educación superior europeo se enfrenta a numerosos cambios que afectan directamente a la conceptualización y funcionamiento de la Universidad, entre los cuales cabe resaltar los siguientes (European Commission, 2003; Warden, 2003; Leitner, 2004; Ramírez et al., 2007; Sánchez y Elena, 2007; De Boer et al., 2012):

- Cambios sociales, con la aparición de nuevas demandas y aspiraciones de los distintos stakeholders (por ejemplo, el sector empresarial y la sociedad en general). Así, la sociedad demanda una mayor rendición de cuentas y justificación del uso de los fondos públicos, como una mayor transparencia informativa.

- Cambios económicos, principalmente relacionados con el descenso, en muchos países, de los fondos públicos para investigación; y la creciente competencia con la educación ofrecida por compañías a través de lo que se denomina "universidades corporativas" que tienen como objetivo el contribuir al proceso de aprendizaje de sus propios empleados a lo largo de toda su vida.

- Cambios culturales, debido a los nuevos enfoques sobre producción de conocimiento y la implantación de nuevos modos de investigación; y

- Cambios políticos, que se reflejan en un creciente nivel de internacionalización de la educación y la investigación, y en una presión por armonizar los diferentes sistemas nacionales universitarios en el contexto europeo a través del conocido proceso de Bolonia y con la creación del Espacio Europeo de Investigación (European Commission, 2010a).

En respuesta a estos desafíos las instituciones universitarias europeas se encuentran actualmente envueltas en un proceso de profundas transformaciones a través de las cuales se pretende mejorar la eficacia, eficiencia y transparencia de estas instituciones con el objetivo último de contribuir al desarrollo y mejora de la competitividad de la economía europea (European Commission, 2010b). Algunos de estos cambios más significativos son los siguientes: nuevos métodos para medir el desempeño y eficiencia de la Universidad; la creación de agencias de acreditación a lo largo de Europa; nuevos procesos de evaluación y sistemas de garantía de la calidad que fortalezcan la transparencia y rendición de cuentas; la institucionalización de nuevos mecanismos de financiación; reformas de legislaciones nacionales para incrementar el nivel de autonomía universitaria; y la introducción de nuevas herramientas para mejorar la gestión interna.

Ante este escenario, la transparencia informativa de las instituciones univer- 
sitarias adquiere, si cabe, un mayor protagonismo, lo cual conlleva la necesidad de realizar una profunda reforma y modernización del sistema universitario en cuanto a la presentación de información, el cual tenga en cuenta las nuevas demandas informativas de sus diferentes stakeholders, incorporando a la información económico-financiera otra clase de información que permita completar la misma y permita justificar las inversiones efectuadas por la institución en su capital intelectual, elemento clave de diferenciación de la misma.

En relación a la importancia concedida a la transparencia informativa de las universidades, cabe destacar dos importantes actuaciones realizadas a nivel nacional, como son:

- La Estrategia Universidad 2015, donde expresamente se señala como uno de los objetivos a alcanzar el conseguir una "mayor transparencia en la rendición de cuentas a la sociedad" (Secretaria de Estado de Universidades, 2008).

- El documento sobre Financiación de las Universidades, presentado por el Ministro de Educación en Consejo de Universidades, el 20 de Enero de 2010, donde en particular se solicita a los gestores universitarios un mayor rigor en la rendición de cuentas señalando la necesidad de que las universidades españolas avancen en el ámbito de la transparencia de la información a través de un Sistema Integrado que facilite información inmediata a cada agente en función de sus necesidades, lo que les permita realizar su toma de decisiones con las máximas garantías de acierto (Consejo de Coordinación Universitaria, 2010).

Sin embargo, tradicionalmente, la rendición de cuentas en el ámbito del sector público ha padecido de cierta miopía en la medida que los instrumentos de transparencia se han centrado en la información financiera y presupuestaria (Martín y Moneva, 2009), obviando cierta información, tales como datos sobre la responsabilidad social de sus actuaciones (Melle, 2007) o sobre sus principales elementos intangibles claves en su creación de valor (Ramírez et al., 2011). Las universidades públicas españolas son un ejemplo de este hecho, ya que la información suministrada se centra en garantizar el control financiero de la entidad, sin prestar atención a las necesidades de otros grupos de interés (Martín, 2006). En este mismo sentido, Gray (2006) considera que la información proporcionada en los estados financieros tradicionales es insuficiente, señalando la necesidad de establecer mecanismos de comunicación y rendición de cuentas más amplios que tengan en consideración las necesidades de los distintos grupos de interés. Igualmente, Coy et al., (2001) recomiendan la ampliación de los límites de las cuentas anuales de las universidades estadounidenses aproximándolos a un nuevo paradigma de rendición de cuentas pública que revele información más comprensiva de la docencia e investigación y de indicadores de los 
esfuerzos y logros alcanzados, prestando una mayor atención a la responsabilidad social de las instituciones de educación superior.

En esta línea, cabe recordar que la investigación contable se encuentra actualmente enmarcada dentro del paradigma de utilidad, el cual señala la necesidad de que la información contable que se suministre sea verdaderamente relevante para la adecuada toma de decisiones de sus usuarios. En consecuencia, y ante las nuevas características del entorno socioeconómico actual del sector de la educación superior europeo, consideramos que las universidades españolas deberían proporcionar toda información relevante sobre el desempeño de la actividad llevada a cabo y sobre sus principales factores claves de éxito -sus intangibles-. Así pues, en nuestra opinión las universidades deberán incorporar en su estrategia de comunicación institucional una mayor atención a sus stakeholders y a sus respectivos intereses informativos, haciéndose necesario incorporar información relevante sobre sus intangibles, como por ejemplo, información sobre aspectos de la calidad de la institución, la imagen corporativa, su responsabilidad social y ambiental, las capacidades, competencias y destrezas de su personal, etc.

De este modo, a lo largo de este trabajo intentaremos evidenciar la importancia concedida por los stakeholders universitarios a la necesidad de que las instituciones de educación superior españolas publiquen información sobre su capital intelectual. Finalmente, y partiendo de los resultados obtenidos en el estudio empírico realizado en este trabajo en relación a qué elementos intangibles se consideran imprescindibles que las universidades suministren información, se presentará una propuesta de Informe de capital intelectual para las universidades españolas.

\section{REVISIÓN DE LA LITERATURA}

La llegada de la sociedad de la información y su evolución hacia la del conocimiento ha situado a los recursos intangibles en una de las fuentes principales de creación de ventaja competitiva sostenible de las organizaciones y de generación de valor y desempeño futuro de las mismas. En este contexto, surge el concepto de capital intelectual como perspectiva estratégica de la "cuenta y razón" de los intangibles de la organización (Bueno, 2002).

En este escenario, y antes de adentrarnos en el concepto de capital intelectual en las instituciones de educación superior, cabe señalar que en este trabajo los términos capital intelectual e intangibles son usados como sinónimos, haciendo referencia a todos aquellos elementos sin sustancia física que son una fuente de beneficios futuros para la organización. La utilización de estos términos depende del contexto en el que nos encontremos. Así, Cañibano et al., (2002), Lev (2003), Sánchez y Elena (2007) señalan que el término intangibles es generalmente empleado en el terreno de la Contabilidad, mientras que el término capi- 
tal intelectual es más utilizado en la literatura de recursos humanos y de gestión de empresas. No obstante, cabe señalar que existen distintos posicionamientos en la literatura sobre capital intelectual. Así, unos autores defienden que el capital intelectual puede ser considerado como el agregado de todos los elementos intangibles que posee una organización (Bontis et al., 1999; Bornemann et al., 1999; Cañibano et al., 2002; etc.), o bien de tan sólo de algunos de ellos (Brooking, 1997; Roos y Roos, 1997; Edvinsson y Malone, 1999; etc.) ${ }^{1}$. Por otro lado, también hay que destacar que algunos autores establecen una diferenciación entre "activos" y "recursos" intangibles, bajo la consideración de que el concepto de recurso es más amplio que el de activo, estableciendo que el término recursos intangibles equivaldría al de capital intelectual, el cual integraría a los activos intangibles contables (Cañibano et al., 2002). Mientras que el término activos intangibles hace referencia exclusivamente a aquellas inversiones de naturaleza intangible que, de acuerdo con las normas contables, pueden ser reconocidas como activos $\mathrm{y}$, consiguientemente, pueden ser reflejadas en el balance de la empresa.

Centrándonos en el ámbito de las instituciones de educación superior, la presentación de información sobre capital intelectual llega a ser de gran relevancia debido, principalmente, al hecho de que el conocimiento es el principal output (resultado) e input (insumo) en estas instituciones. Así, la universidad lo que produce es conocimiento, bien sea a través de la investigación científico-técnica (resultados de investigación, publicaciones, etc.) o bien a través de la docencia (estudiantes formados y relaciones productivas con sus stakeholders). Asimismo, entre sus recursos más valiosos están sus docentes, investigadores, personal de administración y servicios, gobierno universitario y estudiantes, junto con sus procesos organizacionales y redes de relaciones (Warden, 2003; Leitner, 2004). Por lo que puede afirmarse que tanto sus inputs como sus outputs son principalmente intangibles (Cañibano y Sánchez, 2008).

Ahora bien, a pesar de existir una amplia literatura relativa al capital intelectual en el ámbito empresarial español (Azofra et al., 2001; Cañibano et al., 2002; Bordonaba et al., 2006; Salas, 2006; Delgado et al., 2011; etc.), apenas existen estudios que hayan considerado como objeto de análisis el capital intelectual en las instituciones de educación superior (Ortín et al., 2007), lo cual resulta totalmente paradójico pues si hay alguna institución en la que su principal input y output sea el conocimiento ésta es la Universidad.

Siguiendo la definición proporcionada por Cañibano et al., (2002, p. 19), el capital intelectual "es la combinación de los recursos humanos, organizativos y

${ }^{1}$ En este sentido, puede consultarse los trabajos de Kaufmann y Schneider (2004), Simó y Sallán (2008) y Keong (2008), donde se hace una revisión de la principal literatura relativa a las definiciones de capital intelectual. 
relacionales de una empresa", y abarcaría la totalidad de intangibles, tanto formales como informales, siendo más que la simple suma de los elementos que lo integran.

En línea con esta definición, el término "capital intelectual" dentro de las universidades es usado para cubrir todos los activos no tangibles o no físicos de la institución, incluyendo sus procesos, capacidad de innovación, patentes, el conocimiento tácito de sus miembros, sus capacidades, talentos y destrezas, el reconocimiento de la sociedad, su red de colaboradores y contactos, etc. De tal modo que, el capital intelectual es el conjunto de intangibles que "permite a una organización transformar un conjunto de recursos materiales, financieros y humanos en un sistema capaz de crear valor para los stakeholders" (European Commission, 2006, p. 4).

En cuanto a los componentes del capital intelectual universitario, cabe señalar que éste ha sido categorizado de diferentes modos, pero sin duda la clasificación tripartita ha sido la que ha tenido una más amplia aceptación en la literatura especializada (Leitner, 2004; Elena, 2007; Ramírez et al., 2007; Cañibano y Sánchez, 2008; Bezhani, 2010; Bodnár et al., 2010; Casanueva y Gallego, 2010; Márquez, 2010; Secundo et al., 2010). Así, el capital intelectual se representa como formado por los siguientes tres componentes básicos y fuertemente interrelacionados:

- Capital Humano: es el conjunto de conocimiento explícito y tácito del personal de la Universidad (profesores, investigadores, gestores y personal de administración y servicios) adquirido a través de una educación formal e informal y de procesos de actualización incluidos en sus actividades.

- Capital Estructural: es el conocimiento explícito relativo al proceso interno de difusión, comunicación y gestión del conocimiento científico y técnico en la Universidad. El capital estructural se puede dividir en:

- Capital Organizacional: hace referencia al entorno operativo derivado de la interacción entre investigación, gestión y procesos de organización, las rutinas organizativas, valores y cultura corporativa, procedimientos internos, calidad y alcance de los sistemas de información, etc.; y

- Capital Tecnológico: hace referencia a los recursos tecnológicos disponibles en la Universidad, tales como recursos bibliográficos, documentales, archivos, desarrollos técnicos, patentes, licencias, software, bases de datos, etc.

- Capital Relacional: recoge el amplio conjunto de relaciones económicas, políticas e institucionales desarrolladas y mantenidas entre la Universidad y los socios no académicos: firmas, organizaciones no lucrativas, autoridades públicas, gobierno local y sociedad en general, y también recoge 
cómo la Universidad es percibida: su imagen, atractivo, fiabilidad, etc.

Sin embargo, la actual regulación contable restringe el reconocimiento de los intangibles, permitiendo reflejar únicamente en el balance de las organizaciones los intangibles adquiridos (Cañibano et al., 2008). Ante esta situación, son numerosos los organismos, entidades y académicos que, conscientes de la dificultad de incorporar el capital intelectual en los balances con la actual normativa, han optado por proponer la elaboración y presentación de los llamados Informes de Capital Intelectual, los cuales contienen un conjunto de indicadores que contribuyen a mejorar la calidad de la información contable de las organizaciones. Siguiendo esta línea, en el ámbito nacional, la Comisión de Expertos Contables del Ministerio de Economía (ICAC, 2002) recomienda la elaboración y publicación, de forma voluntaria, de un informe de capital intelectual siguiendo las directrices del Proyecto Meritum (Cañibano et al., 2002), el cual consta de tres partes: una visión de la empresa, un resumen de recursos y actividades intangibles y un sistema de indicadores.

Tomando en consideración estos planteamientos, consideramos que la información no financiera de carácter complementario es la vía más apropiada para proveer información acerca de los elementos intangibles de las universidades, evitando así la incorporación de criterios contables que pueden poner en riesgo la calidad y fiabilidad de la información financiera. Por tanto, entendemos que la mejora del sistema contable universitario provendrá de la elaboración y presentación de un nuevo informe complementario a los actuales estados financieros -el informe de capital intelectual-, el cual a través de de un conjunto de indicadores mostrará aquella información más demandada por los diferentes stakeholders sobre los recursos intangibles de la institución.

Con la introducción de la obligatoriedad de presentar este Informe de Capital Intelectual en el sistema de educación superior se daría un paso crucial hacia la nueva gestión universitaria, consiguiendo un doble objetivo: identificar y medir los intangibles para propósitos de gestión y proporcionar información útil a los stakeholders (Ramírez, 2010).

Una de las principales iniciativas relativa a la elaboración y presentación de información sobre capital intelectual en las instituciones de educación superior es el caso de las universidades públicas austriacas, las cuales desde el año 2007 están obligadas a presentar informes de capital intelectual (denominados Wissensbilanz). En concreto la ley universitaria austriaca de 2002 (Austrian University Organisation and Studies Act, 2002), en su artículo 13, estableció la obligación y el marco general para desarrollar este informe de capital intelectual. Según la UG2002 (sección 13, subsección 6), el informe de capital intelectual incluirá, al menos, los siguientes elementos: a) las actividades de la Universidad, los objetivos sociales y voluntarios y las estrategias; b) su capital intelectual, dividido en capital humano, estructural y relacional; c) los procesos 
presentados en el contrato de actuación, incluyendo sus outputs e impactos. Dentro de este informe de capital intelectual, cada Universidad tiene que presentar indicadores de input, output y rendimiento para la investigación, docencia y las actividades de tercera misión. La estructura detallada del informe de capital intelectual universitario, el modo de presentar la información y los indicadores obligatorios a ser publicados fueron regulados mediante una Orden ministerial (Federal Ministry of Education, Science and Culture of Austria, 2006) publicada el 15 de febrero de 2006.

Otras interesantes propuestas de presentación de información sobre capital intelectual son las realizadas por la Universidad Poznan de Economía, en Polonia, donde Fazlagic (2005) presenta un informe de capital intelectual utilizando la metodología propuesta por el Ministerio Danés de Ciencia, Tecnología e Innovación (Danish Ministry of Science, Technology and Innovation, 2000), donde se presenta el capital intelectual en la forma de recursos, actividades y resultados; o la realizada por la organización coreana de investigación no lucrativa ETRI (Electronics and Telecommunications Research Institute), quien a comienzos del año 2001 comenzó a desarrollar una herramienta de gestión eficaz y a establecer un sistema de gestión del conocimiento y desde el año 2004 publica anualmente informes de capital intelectual (ETRI, 2005).

Por otro lado, el Observatory European of Universities (OEU) desarrolló una propuesta de presentación de un informe de capital intelectual específicamente diseñado para universidades y centros de investigación -llamado ICU Report(Sánchez et al., 2006), el cual tiene como finalidad mejorar la transparencia y ayudar a la difusión de los indicadores de capital intelectual de un modo homogéneo. El informe propuesto está constituido por tres secciones fundamentales que describen el movimiento lógico desde la estrategia interna (diseño de la visión y objetivos de la institución) y la gestión hacia un sistema de indicadores (OEU, 2006, p. 211): (a) visión de la institución; (b) recursos y actividades intangibles; (c) sistema de indicadores.

Sin embargo y a pesar de estas experiencias, en la actualidad y a nivel nacional, ni los organismos contables ni las agencias gubernamentales han establecido regulaciones, estándares o normas para elaborar informes de capital intelectual que supongan la existencia de un marco teórico riguroso y consensuado que estandarice los datos a presentar. En este sentido, el estudio empírico realizado en este trabajo supone un primer paso en este camino al poner de manifiesto el grado de importancia concedida por las diferentes universidades públicas españolas a la necesidad de llevar a cabo una política proactiva de publicación de información sobre capital intelectual, y nos servirá de base a la hora de presentar nuestra propuesta de modelo de Informe de capital intelectual para las universidades españolas, el cual pretende servir de guía para ayudar a estas instituciones de cara a presentar información útil a sus stakeholders. 


\section{METODOLOGÍA DE LA INVESTIGACIÓN}

La necesidad de una mayor implicación de las universidades con su entorno y la actual preocupación existente por asegurar su transparencia informativa nos ha llevado a tratar de identificar cuál es el posicionamiento de las universidades públicas españolas sobre la necesidad de divulgar información sobre su capital intelectual. Para cumplir con este objetivo se elaboró un cuestionario que fue enviado a la totalidad de miembros integrantes de los Consejos Sociales de las universidades públicas españolas. Se consideró que estos miembros son una buena muestra del sentir de los usuarios de la información universitaria, al representar a los diferentes colectivos de la sociedad vinculados con las universidades. Una vez sistematizadas y analizadas las diferentes opiniones obtenidas se estuvo en condiciones de presentar una propuesta de informe de capital intelectual para las universidades españolas.

\subsection{Objetivos de la investigación}

De forma específica, se puede considerar como objetivos fundamentales del estudio realizado los dos siguientes:

- Objetivo I: Determinar en qué medida los stakeholders universitarios están interesados en disponer de información relativa al capital intelectual de las universidades públicas españolas, identificando qué partidas intangibles son consideradas más relevantes de cara a su divulgación.

- Objetivo II: Elaborar una propuesta de Informe de capital intelectual para las universidades españolas.

\subsection{Metodología y recogida de datos}

Con el propósito de alcanzar los objetivos anteriormente señalados se procedió, a mediados de mayo de 2011, al envío de un cuestionario online dirigido a los miembros de los Consejos Sociales de las universidades públicas españolas. La metodología del estudio ha sido sintetizada en la ficha técnica adjunta en la Tabla 1.

Tabla 1

Ficha técnica del estudio

\begin{tabular}{ll}
\hline Colectivo objeto de análisis & Stakeholders de las universidades públicas españolas \\
\hline Universo (Población) & Miembros integrantes de los Consejos Sociales de las \\
universidades públicas españolas (1.094) \\
Tamaño de la muestra & 247 \\
\hline
\end{tabular}


Tabla 1 (continuación)

Ficha técnica del estudio

\begin{tabular}{ll}
\hline $\begin{array}{l}\text { Técnica de obtención de } \\
\text { información }\end{array}$ & Encuesta online \\
\hline Periodo de trabajo de campo & Mayo-Julio 2011 \\
\hline Tiempo promedio de encuesta & 7 minutos y 45 segundos \\
\hline Software informático & SPSS $^{\circledR}$ v. 17 \\
\hline
\end{tabular}

Fuente: Elaboración propia.

\subsubsection{Delimitación de la población y selección de la muestra}

Tras realizar una revisión de la literatura especializada (O'dwyer, 2005; Jongbloed et al., 2008; Okunoye et al., 2008; Gaete, 2009; Larrán et al., 2010) se identifica como principales stakeholders en el ámbito universitario a las administraciones públicas, los órganos de gobierno universitario, el personal docente e investigador, el personal de administración de servicios, los estudiantes, los medios de comunicación, los sindicatos y las entidades privadas o públicas que van a contratar a los graduados universitarios (empleadores) o a aplicar la investigación generada en la institución. De este modo, la elección de los miembros de los Consejos Sociales de las universidades públicas españolas está totalmente justificada pues del análisis de la composición concreta de dichos Consejos se ha obtenido que en todos ellos aparecen como miembros: el Rector, el Secretario General, el Gerente, el Secretario del Consejo, un Presidente, un representante del PDI, un representante del PAS, un representante de estudiantes, entre 2 y 6 (generalmente 2) representantes de organizaciones empresariales, entre 2 y 6 (generalmente 2) representantes de organizaciones sindicales, y distintos representantes del Gobierno de la Junta de Comunidades, del Parlamento de la Comunidad Autónoma, del Ayuntamiento, de las Cortes Regionales, de la Federación de Municipios y Provincias, etc., los cuales han sido englobados dentro del colectivo denominado Administraciones Públicas.

De esta manera, la población objeto de estudio ha sido de 1.094 miembros integrantes en los Consejos Sociales de las universidades públicas españolas, obteniéndose respuestas por parte de 247 miembros, lo cual supone un $22.57 \%$ del total. El tamaño de la muestra es considerado suficiente, dado que en una población binominal el error de estimación sería del 5,37\% para un nivel de confianza del $95 \%$.

\subsubsection{Procedimiento de recogida de la información y definición de las variables}

La técnica de recogida de información que se ha utilizado ha sido la encuesta online. A través del correo electrónico se solicita a los miembros de los Consejos Sociales universitarios españoles a participar en nuestra investigación, pro- 
porcionándoles un link de acceso personal a la encuesta (compuesta por preguntas cerradas de escala Likert de 5 puntos).

Para cumplir con los objetivos marcados en el estudio, se solicitó a los encuestados que valorasen con una escala Likert de 5 puntos (donde 1 es nada importante y 5 muy importante) la importancia que otorgaban a la presentación de información sobre diferentes elementos intangibles por parte de las universidades públicas españolas.

En concreto, y basándonos en el modelo Intellectus ${ }^{2}$ (Bueno-CIC, 2003), hemos propuesto 32 elementos intangibles según las características que definen a las instituciones de educación superior, con el fin de establecer su grado de relevancia de cara a su divulgación: doce de ellos correspondientes al capital humano, en tanto que se refiere a las capacidades y destrezas de las personas que pertenecen a la institución; catorce referidos al capital estructural, al hacer referencia a cómo está estructurada la institución y cómo ésta funciona; y dieciséis referidos al capital relacional, ya que recogen las relaciones de la institución con los estudiantes y el mundo exterior.

En la Tabla 2 se muestran los ítems intangibles que definen las tres categorías del capital intelectual así como los resultados obtenidos en relación a la media y desviación típica.

\section{Tabla 2}

Elementos intangibles representativos de cada una de las categorías del capital intelectual en las universidades

\begin{tabular}{|c|c|c|c|c|}
\hline Componentes & & Variables intangibles & Media & $\begin{array}{l}\text { Desviación } \\
\text { típica }\end{array}$ \\
\hline \multirow{12}{*}{$\begin{array}{l}\text { Capital } \\
\text { Humano }\end{array}$} & $\mathrm{CH} 1$ & $\begin{array}{l}\text { Tipología del personal de la Universidad (datos históricos de } \\
\text { crecimiento o disminución de la plantilla, estructura de edades } \\
\text { del personal, relación contractual, etc.) }\end{array}$ & 3.63 & 0.433 \\
\hline & $\mathrm{CH} 2$ & $\begin{array}{l}\text { Cualificación académica y profesional del personal docente e } \\
\text { investigador (\% de docentes, } \% \text { de funcionarios, etc.) }\end{array}$ & 4.60 & 0.321 \\
\hline & $\mathrm{CH} 3$ & $\begin{array}{l}\text { Movilidad de docentes e investigadores (\% de docentes con } \\
\text { estancia, etc.) }\end{array}$ & 4.21 & 0.552 \\
\hline & $\mathrm{CH} 4$ & Productividad científica (libros publicados, artículos, etc.) & 4.58 & 0.365 \\
\hline & $\mathrm{CH} 5$ & Cualificación profesional del PAS & 3.66 & 0.672 \\
\hline & $\mathrm{CH} 6$ & Movilidad de alumnos graduados & 4.37 & 0.327 \\
\hline & $\mathrm{CH} 7$ & Eficiencia del capital humano & 4.54 & 0.413 \\
\hline & $\mathrm{CH} 8$ & $\begin{array}{l}\text { Capacidades y competencias docentes (capacidad didáctica, } \\
\text { innovación docente, calidad docente, dominio de idiomas, } \\
\text { etc.) }\end{array}$ & 4.60 & 0.438 \\
\hline & $\mathrm{CH} 9$ & $\begin{array}{l}\text { Capacidades y competencias investigadoras (calidad de la } \\
\text { investigación, participación en proyectos nacionales e } \\
\text { internacionales, \% de doctores, sexenios, etc.) }\end{array}$ & 4.69 & 0.285 \\
\hline & $\mathrm{CH} 10$ & Capacidad de trabajo en equipo & 4.08 & 0.366 \\
\hline & $\mathrm{CH} 11$ & Capacidad de liderazgo & 3.99 & 0.452 \\
\hline & $\mathrm{CH} 12$ & Actividades de formación & 4.51 & 0.369 \\
\hline
\end{tabular}

${ }^{2}$ Puede consultarse el trabajo de Bueno et al., (2008) donde se recoge las principales aplicaciones y experiencias desarrolladas del Modelo Intellectus. 
Tabla 2 (continuación)

Elementos intangibles representativos de cada una de las categorías del capital intelectual en las universidades

\begin{tabular}{|c|c|c|c|c|}
\hline Componentes & & Variables intangibles & Media & $\begin{array}{l}\text { Desviación } \\
\text { típica }\end{array}$ \\
\hline \multirow{14}{*}{$\begin{array}{l}\text { Capital } \\
\text { Estructural }\end{array}$} & CE1 & $\begin{array}{l}\text { Instalaciones y recursos materiales de apoyo a la cualificación } \\
\text { e innovación pedagógica }\end{array}$ & 4.12 & 0.344 \\
\hline & CE2 & $\begin{array}{l}\text { Instalaciones y recursos materiales de investigación y } \\
\text { desarrollo }\end{array}$ & 4.47 & 0.343 \\
\hline & CE3 & $\begin{array}{l}\text { Actividades y procesos de valoración y cualificación de la } \\
\text { institución }\end{array}$ & 4.31 & 0.383 \\
\hline & CE4 & Estructura organizativa & 4.06 & 0.602 \\
\hline & CE5 & $\begin{array}{l}\text { Gestión y organización de la docencia (redes académicas, } \\
\text { intercambio periódico de docentes extranjeros, incentivos a la } \\
\text { docencia, etc.) }\end{array}$ & 4.33 & 0.402 \\
\hline & CE6 & $\begin{array}{l}\text { Gestión y organización de la investigación (comunicación } \\
\text { interna de resultados, gestión eficiente de proyectos de } \\
\text { investigación, incentivos a la investigación, tesis leídas, etc.) }\end{array}$ & 4.50 & 0.329 \\
\hline & CE7 & Organización de eventos científicos, culturales y sociales & 4.46 & 0.406 \\
\hline & CE8 & $\begin{array}{l}\text { Productividad de los servicios administrativos, académicos y } \\
\text { de apoyo }\end{array}$ & 4.05 & 0.449 \\
\hline & CE9 & Cultura y valores organizacionales & 4.12 & 0.437 \\
\hline & CE10 & $\begin{array}{l}\text { Esfuerzo en innovación y mejora (gasto en innovación, } \\
\text { personal dedicado) }\end{array}$ & 4.58 & 0.352 \\
\hline & CE11 & Calidad en la gestión & 4.54 & 0.394 \\
\hline & CE12 & $\begin{array}{l}\text { Sistema de información (procesos documentados, bases de } \\
\text { datos, utilización de TIC) }\end{array}$ & 4.48 & 0.363 \\
\hline & CE13 & $\begin{array}{l}\text { Capacidad tecnológica (gasto total en tecnología, } \\
\text { disponibilidad y uso de programas informáticos, uso de } \\
\text { intranet/Internet, etc.) }\end{array}$ & 4.49 & 0.394 \\
\hline & CE14 & Propiedad intelectual (patentes, licencias, etc.) & 4.58 & 0.358 \\
\hline \multirow{16}{*}{$\begin{array}{l}\text { Capital } \\
\text { Relacional }\end{array}$} & CR1 & $\begin{array}{l}\text { Eficiencia de la enseñanza graduada (duración media de } \\
\text { estudios, tasa de abandono, tasa de graduación, etc.) }\end{array}$ & 4.63 & 0.295 \\
\hline & CR2 & Satisfacción de los estudiantes & 4.66 & 0.377 \\
\hline & CR3 & Empleabilidad de los graduados & 4.79 & 0.252 \\
\hline & CR4 & $\begin{array}{l}\text { Relaciones con alumnos (capacidad de respuesta a las } \\
\text { necesidades de los estudiantes, relaciones permanentes con } \\
\text { exalumnos, etc.) }\end{array}$ & 4.29 & 0.359 \\
\hline & CR5 & $\begin{array}{l}\text { Relaciones con el mundo empresarial (spin-offs, contratos y } \\
\text { proyectos de } I+D \text {, etc.) }\end{array}$ & 4.79 & 0.271 \\
\hline & CR6 & $\begin{array}{l}\text { Relaciones con la sociedad en general (representación } \\
\text { institucional en entidades externas, colaboración en proyectos } \\
\text { nacionales e internacionales, etc.) }\end{array}$ & 4.47 & 0.354 \\
\hline & CR7 & $\begin{array}{l}\text { Aplicación y difusión de la investigación (difusión de } \\
\text { resultados, adecuación social de la investigación) }\end{array}$ & 4.57 & 0.374 \\
\hline & CR8 & Relaciones con medios de comunicación & 4.01 & 0.547 \\
\hline & CR9 & Imagen de la Universidad & 4.65 & 0.313 \\
\hline & CR10 & $\begin{array}{l}\text { Colaboraciones y contactos con organismos públicos y } \\
\text { privados }\end{array}$ & 4.50 & 0.348 \\
\hline & CR11 & Colaboración con otras universidades & 4.56 & 0.284 \\
\hline & CR12 & Vínculos estratégicos & 4.42 & 0.335 \\
\hline & CR13 & Relaciones con instituciones de calidad & 4.44 & 0.341 \\
\hline & CR14 & Notoriedad regional, nacional e internacional de la Universidad & 4.47 & 0.405 \\
\hline & CR15 & Compromiso social y cultural & 4.50 & 0.398 \\
\hline & CR16 & Responsabilidad medioambiental & 4.49 & 0.434 \\
\hline
\end{tabular}

Fuente: Elaboración propia. 


\subsubsection{Tratamiento de datos}

Las respuestas obtenidas han sido sometidas a un análisis descriptivo en función de las características de cada una de las preguntas del cuestionario.

Para evaluar la validez discriminante de los ítems y variables definidas y examinar la estructura subyacente de los datos, se han utilizado cuatro medidas de ajuste clásicas, el porcentaje de varianza explicada, el estadístico de KaiserMeyer-Olkin (KMO), el contraste de esfericidad de Barlett y el coeficiente alpha de Cronbach (Hair, 1999).

Tabla 3

Análisis factorial de las categorías del capital intelectual

\begin{tabular}{lcccc}
\hline Categorías de Capital Intelectual & $\begin{array}{c}\text { Varianza total } \\
\text { explicada }\end{array}$ & KMO* & $\begin{array}{c}\text { Esfericidad de } \\
\text { Barlett }\end{array}$ & $\begin{array}{c}\boldsymbol{\alpha} \text { de } \\
\text { Cronbach }\end{array}$ \\
\hline Capital Humano (12 ítems) & $43,57 \%$ & 0.785 & $287.91(0.000)$ & 0.849 \\
Capital Estructural (14 ítems) & $48.43 \%$ & 0.748 & $436.49(0.000)$ & 0.914 \\
Capital Relacional (16 ítems) & $50.83 \%$ & 0.780 & $576.79(0.000)$ & 0.930 \\
\hline
\end{tabular}

* Prueba de adecuación muestral de Kaiser-Meyer-Olkin

Fuente: Elaboración propia.

Los coeficientes de estos contrastes muestran valores altamente aceptables, garantizando la validez de los resultados obtenidos. El coeficiente alpha de Cronbach señala una consistencia aceptable de la escala y los coeficientes de esfericidad de Barlett y el estadístico KMO indican una correlación significativa entre los ítems que constituyen cada categoría.

Asimismo, la matriz de componentes rotados obtenida de la aplicación del método varimax, recogida en la Tabla 4, nos permite comprobar cómo la estructura de cada factor (capital humano, estructural y relacional) es consistente, pues todas las variables intangibles identificadas en nuestro trabajo cargan sobre el factor al que pertenecen.

Tabla 4

Matriz de componentes rotados

\begin{tabular}{cccc}
\hline $\begin{array}{c}\text { Variables } \\
\text { intangibles }\end{array}$ & $\begin{array}{c}\text { Factor } \mathbf{1} \\
\text { CH }\end{array}$ & $\begin{array}{c}\text { Factor 2 } \\
\text { CE }\end{array}$ & $\begin{array}{c}\text { Factor 3 } \\
\text { CR }\end{array}$ \\
\hline $\mathrm{CH} 1$ & $\mathbf{0 . 4 3 9}$ & -0.148 & 0.097 \\
$\mathrm{CH} 2$ & $\mathbf{0 . 6 2 9}$ & 0.143 & 0.051 \\
$\mathrm{CH} 3$ & $\mathbf{0 . 5 9 0}$ & 0.384 & 0.197 \\
$\mathrm{CH} 4$ & $\mathbf{0 . 7 3 1}$ & 0.213 & 0.244 \\
$\mathrm{CH} 5$ & $\mathbf{0 . 3 6 1}$ & 0.098 & 0.188 \\
$\mathrm{CH} 6$ & $\mathbf{0 . 5 4 4}$ & 0.224 & 0.340 \\
$\mathrm{CH} 7$ & $\mathbf{0 . 5 5 6}$ & 0.242 & 0.091 \\
\hline
\end{tabular}


Tabla 4 (continuación)

Matriz de componentes rotados

\begin{tabular}{|c|c|c|c|}
\hline $\begin{array}{c}\text { Variables } \\
\text { intangibles }\end{array}$ & $\begin{array}{c}\text { Factor } 1 \\
\mathrm{CH}\end{array}$ & $\begin{array}{c}\text { Factor } 2 \\
\text { CE }\end{array}$ & $\begin{array}{c}\text { Factor } 3 \\
\text { CR }\end{array}$ \\
\hline $\mathrm{CH} 8$ & 0.755 & 0.167 & 0.239 \\
\hline $\mathrm{CH} 9$ & 0.575 & 0.204 & 0.162 \\
\hline $\mathrm{CH} 10$ & 0.422 & 0.352 & 0.199 \\
\hline $\mathrm{CH} 11$ & 0.403 & 0.292 & 0.122 \\
\hline $\mathrm{CH} 12$ & 0.505 & 0.083 & 0.483 \\
\hline CE1 & 0.303 & 0.518 & -0.068 \\
\hline CE2 & 0.155 & 0.613 & 0.161 \\
\hline CE3 & 0.335 & 0.541 & 0.208 \\
\hline CE4 & 0.371 & 0.561 & 0.177 \\
\hline CE5 & 0.146 & 0.507 & 0.370 \\
\hline CE6 & 0.371 & 0.561 & 0.177 \\
\hline CE7 & -0.111 & 0.460 & 0.371 \\
\hline CE8 & 0.455 & 0.480 & -0.012 \\
\hline CE9 & 0.246 & 0.465 & 0.332 \\
\hline CE10 & 0.179 & 0.740 & 0.132 \\
\hline CE11 & 0.121 & 0.638 & 0.209 \\
\hline CE12 & 0.130 & 0.591 & 0.169 \\
\hline CE13 & 0.202 & 0.599 & 0.144 \\
\hline CE14 & -0.060 & 0.709 & 0.324 \\
\hline CR1 & 0.105 & 0.369 & 0.603 \\
\hline CR2 & 0.162 & 0.030 & 0.677 \\
\hline CR3 & 0.236 & 0.221 & 0.651 \\
\hline CR4 & 0.232 & 0.416 & 0.454 \\
\hline CR5 & 0.030 & 0.091 & 0.718 \\
\hline CR6 & 0.163 & 0.212 & 0.577 \\
\hline CR7 & 0.343 & 0.164 & 0.533 \\
\hline CR8 & 0.232 & 0.413 & 0.426 \\
\hline CR9 & 0.255 & 0.084 & 0.595 \\
\hline CR10 & 0.374 & 0.209 & 0.526 \\
\hline CR11 & 0.205 & -0.080 & 0.591 \\
\hline CR12 & 0.061 & 0.334 & 0.512 \\
\hline CR13 & 0.088 & 0.387 & 0.519 \\
\hline CR14 & 0.378 & 0.235 & 0.578 \\
\hline CR15 & -0.047 & 0.462 & 0.542 \\
\hline CR16 & 0.227 & 0.104 & 0.526 \\
\hline
\end{tabular}

Fuente: Elaboración propia.

\subsection{Análisis de resultados del estudio empírico}

A continuación comentamos, para cada uno de los objetivos marcados, los principales resultados obtenidos a través del estudio empírico realizado en este trabajo. 


\subsubsection{Objetivo 1: Importancia concedida a la presentación de información sobre diferentes elementos intangibles}

En primer lugar cabe destacar que un alto porcentaje de los encuestados, el $89.1 \%$, considera fundamental que las universidades españolas suministren información sobre su capital intelectual. Diferenciando por colectivos de usuarios, se obtuvo que la práctica totalidad de los usuarios -Administraciones Públicas $(89,4 \%)$, alumnos $(100 \%)$, organizaciones empresariales $(86,2 \%)$, PDI $(95,5 \%)$ y gobierno universitario $(97,4 \%)$, miembros del PAS $(66,7 \%)$ y de organizaciones sindicales (76,5\%)- consideran que la presentación de información sobre capital intelectual por parte de las universidades aumentaría la relevancia de la información contenida en el actual modelo contable universitario.

Posteriormente, con el fin de identificar aquellas partidas intangibles que, en opinión de los miembros de los Consejos Sociales, se puede considerar como relevante o muy relevante su divulgación, se ha marcado como requisitos que las partidas en cuestión alcancen una valoración media y una mediana igual o superior a 4 puntos combinada con la presencia de un percentil 25 mínimo de 4 puntos y un percentil 75 mínimo de 5 puntos. En definitiva, lo que se pretende es que el grueso de la distribución de sus valoraciones quede concentrado en puntuaciones muy altas -cercanas a 5 puntos-. Asimismo, se ha considerado que para catalogar como imprescindible la divulgación de alguna partida intangible, ésta además de los requisitos anteriores debe de presentar una valoración media superior a 4,5 puntos.

Figura 1

Elementos intangibles considerados imprescindibles divulgar

\begin{tabular}{|c|c|c|}
\hline Capital Humano & Capital Estructural & Capital Relacional \\
\hline $\begin{array}{l}\text { - Cualificación } \\
\text { académica y } \\
\text { profesional del PDI } \\
\text { - Movilidad de } \\
\text { docentese } \\
\text { investigadores } \\
\text { - Productividad } \\
\text { científica } \\
\text { - Capacidades y } \\
\text { competencias } \\
\text { docentes }\end{array}$ & $\begin{array}{l}\text { - Esfuerzo en } \\
\text { innovación y } \\
\text { mejora } \\
\text { - Propiedad } \\
\text { Intelectual } \\
\text { - Calidad en la } \\
\text { gestión }\end{array}$ & $\begin{array}{l}\text { - Empleabilidad de } \\
\text { los graduados } \\
\text { - Satisfacción de los } \\
\text { estudiantes } \\
\text { - Eficiencia de la } \\
\text { enseñanza } \\
\text { graduada } \\
\text { - Relaciones con el } \\
\text { mundo empresarial } \\
\text { - Imagen de la } \\
\text { Universidad } \\
\text { - Colaboración con } \\
\text { otras Universidades }\end{array}$ \\
\hline
\end{tabular}

Fuente: Elaboración propia.

Respecto a este objetivo, cabe destacar la existencia general de una elevada valoración media otorgada a la divulgación de información de las distintas partidas intangibles relativas tanto al capital humano, al estructural como al rela- 
cional, lo que evidencia un fuerte énfasis en la necesidad de que las universidades presenten información sobre su capital intelectual. En concreto, del análisis de los datos obtenidos en los distintos estadísticos (media, mediana, desviación típica, percentil 25 y 75) se puede catalogar como imprescindible la divulgación de los siguientes elementos intangibles (véase Figura 1).

\subsubsection{Objetivo 2: Propuesta de un informe de capital intelectual}

A partir de la revisión de la principal literatura existente sobre informes de capital intelectual en instituciones de educación superior y centros de investigación (Bueno, 2002, 2003; Leitner, 2004; Fazlagic, 2005; Altenburger and Schaffhauser, 2005; Sánchez et al., 2006, 2009; Ramírez et al., 2007; Cañibano y Sánchez, 2008; Schaffhauser, 2009; Bezhani, 2010; Bodnár et al., 2010; Silvestri y Veltri, 2011; etc.), y teniendo en consideración los resultados obtenidos en el análisis empírico realizado en este trabajo, hemos desarrollado una propuesta de modelo de Informe de capital intelectual para las universidades españolas.

Los llamados Informes de Capital Intelectual son instrumentos especialmente diseñados para la identificación, medición, gestión y difusión de intangibles en las organizaciones, siendo aplicados en diferentes sectores. En concreto, esta herramienta es usada para identificar y ofrecer información sobre la estrategia, objetivos, visiones, actividades y recursos intangibles claves de la organización, y está basada en indicadores (financieros y no financieros).

Por lo tanto, el informe de capital intelectual debe cumplir dos funciones primordiales (European Commission, 2006):

- Como herramienta interna de gestión, que es necesaria para identificar, desarrollar y asignar recursos, definir estrategias, establecer prioridades de actuación, vigilar el desarrollo de los resultados de las universidades y facilitar la toma de decisiones, y

- Como medio para facilitar la comunicación entre las universidades y terceras partes interesadas en la misma, con la finalidad de captar recursos económicos, humanos, etc.

En este punto es interesante vincular el concepto de Informe de Capital Intelectual con otros elementos de control que se puedan implementar en la planificación estratégica de las universidades, como el de cuadro de mando integral o un sistema de contabilidad analítica. En nuestra opinión, el Informe de Capital Intelectual es un concepto más específico y supondrá la herramienta más adecuada para transmitir información sobre los factores clave de la universidad, pues además de servir como herramienta de gestión para la dirección estratégica de las universidades, también sirve como herramienta de comunicación, favoreciendo la creación de vínculos con el exterior a través de la información interna. 
Los Informes de Capital Intelectual son un instrumento que nos permitirá conocer cuál es la política de la universidad respecto a los intangibles que integran su capital intelectual, comunicando a todos los interesados las capacidades, recursos y compromisos de la institución universitaria en relación con esos elementos que actualmente se consideran fundamentales, y que además sirve para explicar el papel del capital intelectual en el proceso de creación de valor de las universidades e incrementar la eficiencia en su gestión. Por tanto, el informe de capital intelectual sirve no solo como documento sino también como dinamizador de actitudes para la valoración y gestión del componente intangible de las universidades.

Nuestro objetivo final es elaborar un modelo de Informe de CI abierto y flexible, de aplicación generalizada y fácilmente descifrable, claro e inequívoco para la gran mayoría de los stakeholders universitarios interesados en la información institucional que es (o debería ser) divulgada regularmente por las universidades.

El proceso de implantación de dicho Informe de CI en las universidades constituye, básicamente, tres fases:

\section{- Definición de los objetivos estratégicos en el área de los intangibles.}

Dentro de esta fase, en primer lugar se ha de discutir los objetivos y estrategias corporativos, lo cual lleva a los gestores a centrarse en los procesos de creación de valor esenciales que deben ser medidos, documentados y comunicados. La definición del marco estratégico de la organización facilitará posteriormente la formulación de los objetivos estratégicos en el área de los intangibles, los cuales definen las áreas en donde se deben crear o mejorar destrezas específicas, estructuras y relaciones.

\section{- Selección de indicadores y recogida de datos.}

A continuación se debe formular indicadores válidos para cada categoría del capital intelectual. Esta fase resulta crítica, pues el interés y la viabilidad del modelo de informe de CI depende sobre todo de las características y de la calidad de los indicadores utilizados y de las fuentes de obtención de datos para su construcción. Durante el proceso de recogida de datos, es muy importante motivar continuamente a los empleados para realizar dicha tarea y convencerles de los beneficios de un informe de CI.

\section{- Tipología de divulgación (formato, soportes, periodicidad).}

La tipificación del proceso de divulgación debe también ser tenida en cuenta, puesto que ésta puede condicionar significativamente la estructura final del modelo. Las tres cuestiones básicas a definir son: a) el formato de presentación; b) el soporte o los soportes para la divulgación: Internet, edición limitada en papel, difusión a través de los medios de comunica- 
ción social, displays o circuitos de imagen internos, etc.; y c) la periodicidad.

En cuanto al formato a utilizar para la divulgación de información sobre capital intelectual, es necesario poner mucho cuidado en su definición, puesto que éste de ser claro, breve y entendible incluso para los no especialistas.

Figura 2

Estructura general del modelo de Informe de $\mathrm{Cl}$ en las Universidades

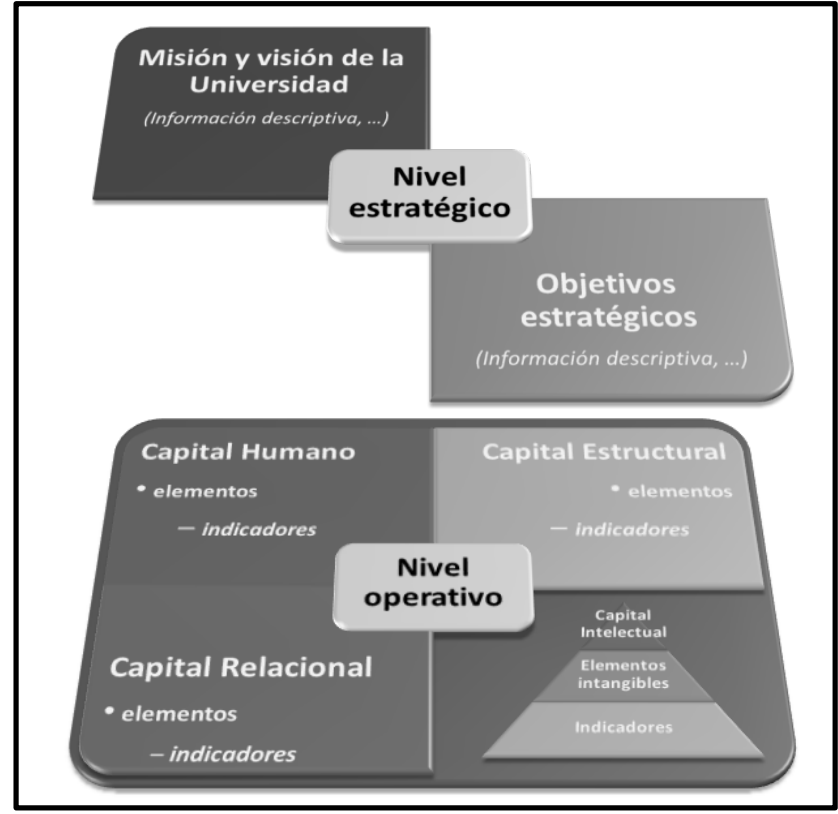

Fuente: Elaboración propia.

Nuestra propuesta para el formato de divulgación contempla un informe con dos partes distintas (véase Figura 2):

- Una parte esencialmente descriptiva, que engloba todo el nivel estratégico de la institución y cuyo desarrollo depende del mayor o menor grado de interés de la entidad en divulgar los contenidos de su planificación estratégica. Para la adecuada comprensión y lectura de los indicadores, debe ser hecha, por lo menos, una descripción completa de la misión y de la visión de la institución y la presentación sintética de los objetivos estratégicos trazados en función de dicha misión y visión.

- Una segunda parte corresponde al nivel operacional, que está constituida por el conjunto de indicadores relativos a los recursos de capital intelectual de la Universidad (capital humano, capital estructural y capital rela- 
cional). Para cada componente son considerados diversos elementos, a los cuales puede corresponder una o varias variables, que son representadas por indicadores agregados. Los valores de los indicadores pueden ser calculados y presentados para diferentes períodos sucesivos, lo que permite un análisis comparativo en una base temporal.

De este modo, nuestro objetivo es presentar una estructura de Informe de CI que sea fácilmente entendible y comprensible por cualquier usuario no especializado, y que permita establecer comparaciones con relativa facilidad entre diferentes momentos de tiempo de la institución o entre instituciones diferentes.

A continuación, se presenta de forma resumida, la estructura general de nuestra propuesta de modelo de Informe de capital intelectual para las universidades españolas, la cual estará formada por tres secciones ${ }^{3}$ :

\section{Sección 1. Misión y Visión de la Universidad}

En esta sección se presenta una breve descripción de la misión y visión de la Universidad, así como los objetivos estratégicos específicos definidos para el periodo en curso vinculados a los recursos intangibles (humanos, estructurales y relacionales) de la institución y las líneas de actuación a seguir para conseguir con éxito esos objetivos. Esta sección se presenta en forma de narrativa y su extensión será normalmente de 3-4 páginas.
$\checkmark$ ¿Cuáles son los principales servicios que proporciona la Universidad?
$\checkmark$ ¿Cuáles son los principales objetivos de la Universidad?
$\checkmark$ ¿Qué la diferencia de otras instituciones?
$\checkmark$ ¿Cuáles son los objetivos estratégicos de la Universidad vinculados con los recursos intangibles de la institución?

\section{Sección 2. Recursos intangibles}

Hace referencia a la presentación comentada de nuestra propuesta de modelo

\footnotetext{
${ }^{3}$ Nuestra propuesta de estructura de informe de capital intelectual universitario en tres secciones está basada en la propuesta presentada por Sánchez et al., (2006). La principal diferencia entre ambas propuestas se encuentra en la batería de indicadores presentados, así como que en nuestra propuesta se vincula directamente dichos indicadores con los elementos intangibles concretos a los que intenta medir y que han sido validados previamente en nuestro estudio empírico. Por lo que nuestro trabajo supone un paso hacia la validación y consenso sobre los elementos que deberían integrar un informe de capital intelectual universitario. Por su parte, Sánchez et al., (2006) presentan una propuesta más amplia de indicadores (43 indicadores financieros y no financieros) para medir el capital intelectual en las universidades, los cuales están organizados por objetivos estratégicos, centrándose tanto en recursos como actividades intangibles. Así, pues otra importante diferencia es la incorporación de actividades intangibles que la universidad debe llevar a cabo para desarrollar los recursos intangibles.
} 
de identificación de los bienes intangibles que componen el capital intelectual de la Universidad.

$\checkmark$ ¿Cuáles son los recursos intangibles (humanos, estructurales y relacionales) necesarios para alcanzar los objetivos estratégicos de la institución?

\section{Sección 3. Batería de indicadores para los elementos del capital intelectual}

Finalmente se recogería una batería de indicadores relativos a los recursos del capital intelectual que la Universidad utiliza actualmente. Los indicadores son desglosados en los respectivos elementos del capital intelectual y se realizarán comparaciones con períodos anteriores y con información previsional.

A la hora de elaborar nuestra propuesta de indicadores, además de servirnos de base la revisión de la literatura existente relativa a los informes de capital intelectual en instituciones e educación superior, también se ha tenido en cuenta diversos trabajos donde se recopilan cuadros de indicadores desarrollados en distintas universidades españolas o extranjeras (González et al., 2010; González y Rodríguez, 2010; Ramírez y Baidez, 2011; Larrán y Benayas, 2011). Así, en el trabajo de González et al., (2010) se realiza un análisis y estudio a fondo sobre las distintas memorias de sostenibilidad editadas por las universidades españolas en los últimos años, donde se recogen indicadores relativos a recursos (estructura operativa, oferta formativa, recursos humanos, recursos materiales y tecnológicos, información económica), compromiso con el alumnado, compromiso con el personal, compromiso social, compromiso ambiental, compromiso con el sector empresarial y las instituciones, compromiso con la mejora continua, etc. En el trabajo de Ramírez y Baidez (2011) se revisan las principales aplicaciones del cuadro de mando integral en las universidades españolas, detallando el plan estratégico de dichas universidades y su propuesta de batería de indicadores. Por su parte, en el trabajo de González y Rodríguez (2010) se recopila información sobre las principales iniciativas existentes, a nivel internacional, sobre modelos de capital intelectual e indicadores en las universidades, presentándose una propuesta de indicadores de capital intelectual para la universidad pública colombiana. Finalmente, en el trabajo de Larrán y Benayas (2011) se presenta, para el caso de las universidades públicas andaluzas, una propuesta de indicadores en diferentes áreas temáticas, tales como gobernanza, compromiso con el alumnado, profesorados y PAS, medio ambiente, sociedad, empresas, mejora continua, etc.

Con todo ello, y basándonos en los resultados obtenidos en el estudio empírico realizado en este trabajo, estamos en condiciones de conocer cuáles son los aspectos claves que no deben faltar en una presentación de información sobre capital intelectual por parte de las universidades españolas de cara a satisfacer las necesidades de sus stakeholders. De este modo, nuestra propuesta de modelo de Informe de capital intelectual estará basada en la construcción de una batería 
de indicadores básicos o generales que aglutinará todos aquellos elementos intangibles que se consideran "imprescindibles" divulgar a la sociedad (véase Tabla 5).

\section{Tabla 5}

Propuesta de Modelo de Informe de Capital Intelectual para Universidades (Sección 3. Indicadores)

\begin{tabular}{|c|c|c|c|c|}
\hline NIVEL OPERACIONAL & & & & \\
\hline Elementos intangibles & Indicadores & $\mathrm{n}-1$ & $\mathbf{n}$ & $n+1$ \\
\hline \multicolumn{5}{|l|}{ CAPITAL HUMANO } \\
\hline $\begin{array}{l}\text { Cualificación académica y } \\
\text { profesional del PDI }\end{array}$ & $\begin{array}{l}\% \text { de PDI doctores } \\
\mathrm{N}^{\circ} \text { de profesores habilitados } \\
\% \text { del personal administrativo, técnico y auxiliar con graduación }\end{array}$ & & & \\
\hline Movilidad docente & $\%$ de docentes con estancias en otras Universidades & & & \\
\hline Productividad científica & $\begin{array}{l}\text { Tasa de participación en proyectos de investigación } \\
\text { Proporción de sexenios de investigación } \\
\text { Producción de tesis doctorales } \\
\mathrm{N}^{\circ} \text { de publicaciones científicas }\end{array}$ & & & \\
\hline $\begin{array}{l}\text { Capacidades y } \\
\text { competencias docentes }\end{array}$ & $\begin{array}{l}\text { Total PDI / total alumnos } \\
\mathrm{N}^{\circ} \text { de participantes en programas de formación } \\
\mathrm{N}^{\circ} \text { de horas dedicadas a la formación docente }\end{array}$ & & & \\
\hline \multicolumn{5}{|l|}{ CAPITAL ESTRUCTURAL } \\
\hline $\begin{array}{l}\text { Esfuerzo en innovación y } \\
\text { mejora }\end{array}$ & $\begin{array}{l}\text { Gasto en } 1+\mathrm{D}+\mathrm{i} \\
\mathrm{N}^{\circ} \text { de proyectos de } \mathrm{I}+\mathrm{D}+\mathrm{i} \text { en desarrollo }\end{array}$ & & & \\
\hline Propiedad intelectual & $\begin{array}{l}\text { Producción de patentes } \\
\text { Producción científica }\end{array}$ & & & \\
\hline Calidad en la gestión & Certificaciones de calidad obtenidas & & & \\
\hline \multicolumn{5}{|l|}{ CAPITAL RELACIONAL } \\
\hline $\begin{array}{l}\text { Empleabilidad de } \\
\text { graduados }\end{array}$ & $\begin{array}{l}\text { Tasa de empleo encajado } \\
\text { Tiempo transcurrido hasta el primer empleo }\end{array}$ & & & \\
\hline Satisfacción de estudiantes & $\begin{array}{l}\text { Encuestas de satisfacción de los graduados con los } \\
\text { estudios realizados } \\
\% \text { de preinscritos en primera opción respecto a la oferta } \\
\text { total de plazas }\end{array}$ & & & \\
\hline $\begin{array}{l}\text { Eficiencia de enseñanza } \\
\text { graduada }\end{array}$ & $\begin{array}{l}\text { Tasa de abandono } \\
\text { Tasa de graduación } \\
\text { Tasa de rendimiento }\end{array}$ & & & \\
\hline $\begin{array}{l}\text { Relaciones con el Mundo } \\
\text { Empresarial }\end{array}$ & $\begin{array}{l}\text { Tasa de realización de prácticas en empresas } \\
\text { Valoración de la formación de universitarios por colectivo } \\
\text { empleador } \\
\mathrm{N}^{\circ} \text { de acuerdos de colaboración en proyectos y actividades } \\
\text { con empresas }\end{array}$ & & & \\
\hline $\begin{array}{l}\text { Colaboración con otras } \\
\text { universidades }\end{array}$ & $\%$ de docentes recibidos de otras Universidades & & & \\
\hline Imagen de la Universidad & $\begin{array}{l}\text { Valoración de la opinión de la sociedad sobre la } \\
\text { Universidad } \\
\text { Programas de doctorado con mención de calidad } \\
\text { Tasa de estudiantes de universidades extranjeras en títulos } \\
\text { de postgrado }\end{array}$ & & & \\
\hline
\end{tabular}

Fuente: Elaboración propia 
No obstante, además de estos indicadores estándares propuestos, también será aconsejable que posteriormente cada Universidad concreta desarrolle indicadores específicos atendiendo a la propia idiosincrasia de su institución.

Finalmente, haremos referencia a algunos aspectos importantes a considerar en la presentación de información sobre capital intelectual en las universidades: cómo recoger los datos necesarios, quién debería ser responsable de esta recogida de datos, y con qué frecuencia se debe presentar el Informe de CI.

\section{- Recogida de datos: ¿Cómo?}

El proceso de recogida de datos podría variar de una institución a otra, dependiendo del desarrollo de sus bases de datos internas (Sánchez et al., 2006). Las principales fuentes de información podrían ser las siguientes (Cañibano et al., 2002, p. 42):

- Las bases de datos de la institución. A este respecto, cabe señalar la necesidad de que las universidades realicen importantes esfuerzos en implantar un almacén de datos que comprenda la amplia variedad de bases de datos diferentes existentes en la institución, lo cual permitirá mejorar su eficiencia.

- Documentos internos. Gran parte de la información requerida para la elaboración de los informes de CI se encuentra dispersa en una gran diversidad de diferentes documentos.

- Cuestionarios. Una importante parte de información contenida en un Informe de CI es cualitativa, por lo que, puede ser necesario llevar a cabo encuestas entre diferentes niveles de la Universidad para capturarla. Asimismo, los cuestionarios pueden ser usados para adaptar un Informe de CI a la idiosincrasia de una Universidad e identificar posiciones enfrentadas y potenciales grupos problemáticos.

- Fuentes externas. Es importante tener en cuenta la percepción que los actores externos tienen sobre una Universidad, e identificar las oportunidades externas y barreras.

Por otro lado, es importante subrayar que la información sobre capital intelectual debería ser recogida de un modo sistemático, para garantizar la consistencia en los datos. Además, según señalan Sánchez et al., (2006), es más significativo mostrar los datos como una media de los 3 últimos años ${ }^{4}$, lo cual permitirá mostrar mejor las tendencias generales y evitar comportamientos y situaciones temporales.

\footnotetext{
${ }^{4}$ De este modo, un año promediado con los dos últimos será comparado con el año anterior también promediado con los dos últimos.
} 


\section{- Recogida de datos: ¿Quién?}

Puesto que los datos necesarios tienen diversa naturaleza, la información debe ser obtenida de diferentes departamentos de la Universidad. Compartimos la opinión de Sánchez et al., (2006) de que la situación ideal sería la de crear una oficina de recogida de datos central que se pusiera en contacto con los diferentes departamentos. En caso de existir en la universidad una Oficina de preparación del Plan Estratégico, se considera que los individuos encargados del desarrollo de los sistemas de medida del Informe de CI pueden estar integrados en dicha Oficina, puesto que se ambos documentos están muy relacionados.

Por último, señalar que es fundamental que las altas autoridades académicas estén comprometidas en la preparación del Informe de Capital Intelectual de la institución.

\section{- Frecuencia de presentación de Informes de CI}

Por último, es interesante reflexionar sobre el período de presentación de los citados Informes de CI. ¿Cuál es el período más adecuado: anual, plurianual, académico?

Aunque en el futuro parece posible la disponibilidad online de este tipo de información institucional sobre intangibles, actualmente lo más aceptable es definir periodicidades de divulgación coincidentes con otras acciones de comunicación institucional. Así, para el caso de las universidades, Sánchez et al., (2006) sugieren que la preparación del Informe de CI debería tener la misma frecuencia que la publicación del Plan Estratégico, puesto que estos documentos son complementarios. Con lo que, el Informe de CI completo podría ser publicado cada dos o tres años, haciéndole anualmente un seguimiento. Sin embargo, en nuestra opinión, la publicación de los Informes de CI de las Universidades debería ser como mínimo anual.

\section{CONCLUSIONES A MODO DE RESUMEN}

En el actual contexto de la Sociedad del Conocimiento las instituciones de educación superior europeas se caracterizan por estar envueltas en un proceso de profundas transformaciones para mejorar su eficacia, eficiencia y transparencia, lo cual afecta directamente a la conceptualización y al funcionamiento de estas instituciones y a su modelo de presentación de información.

En este contexto, y ante la creciente preocupación social por establecer procesos de rendición de cuentas en las instituciones de educación superior públicas y por asegurar la transparencia informativa de estas instituciones, se plantea la necesidad de realizar importantes cambios en los actuales sistemas de comunicación universitarios, de tal forma que se incorpore información sobre el capital intelectual de estas instituciones. A través de la presentación de esta nueva 
información los interesados externos podrán disponer de información fiable y comparable sobre el desempeño de las instituciones de educación superior en todos sus ámbitos de actuación y podrán así formar juicios de valor y tomar las decisiones correspondientes.

En este sentido, estamos totalmente de acuerdo con el Observatory of the European University (2006) afirmando que, en un futuro no muy lejano, la divulgación de información sobre el capital intelectual llegará a ser obligatoria en las universidades, lo cual es principalmente debido al hecho de que el conocimiento es el principal output (resultado) e input (insumo) en estas instituciones y a que éstas son consideradas actores institucionales críticos en los sistemas de innovación nacional dentro de la actual Economía basada en el conocimiento.

Sin embargo, actualmente en la mayoría de los países se verifica una total ausencia de obligación o recomendación de presentar información sobre capital intelectual por parte de las universidades, con la excepción del caso de las universidades austriacas y suecas.

Ante esta situación, el objetivo principal de este trabajo ha sido desarrollar una propuesta de modelo de divulgación de información institucional específicamente referida al capital intelectual. Esta propuesta de divulgación es realizada a través de la elaboración y presentación de un Informe de Capital Intelectual para las universidades españolas, lo cual supondrá un saludable ejercicio de transparencia por parte de dichas instituciones al facilitar a los usuarios el acceso a un tipo de información relevante para su toma de decisiones. El informe de capital intelectual pretende identificar, medir y poner en valor los recursos intangibles de la institución, mediante la comunicación de información sobre la visión, estrategia, objetivos, capacidades y recursos basada en indicadores financieros y no financieros. Por tanto, el informe de capital intelectual persigue dos objetivos fundamentales. Por una parte, es una herramienta de gestión del conocimiento, que facilita la toma de decisiones internas para asignar recursos y desarrollar una estrategia y, por otra, favorece la creación de vínculos con el exterior a través de la información interna.

Para el desarrollo de nuestra propuesta de Informe de capital intelectual universitario se ha partido de la revisión de la principal literatura existente sobre el tema y de los resultados obtenidos en el estudio empírico realizado en este trabajo sobre la opinión de los usuarios de la información contable universitaria sobre la necesidad de que las universidades españolas lleven a cabo una política proactiva de publicación de información sobre capital intelectual, y concretamente sobre qué partidas intangibles consideran imprescindibles que las universidades suministren información.

Ahora bien, se ha de tener en cuenta que el capital intelectual es específico de cada organización y su valor y relevancia depende de su potencial contribución a los objetivos claves de la institución, por lo que no existe un modelo 
único y homogéneo de presentación de información sobre capital intelectual en las universidades. En este sentido, de cara a obtener un equilibrio entre estandarización e idiosincrasia de cada institución universitaria, nuestro trabajo propone, en primer lugar, que todas universidades españolas presenten información sobre un conjunto de elementos intangibles básicos o generales que sean útiles para todas las instituciones (los cuales han sido identificados en el estudio empírico realizado en este trabajo); y en segundo lugar, que cada Universidad presente un conjunto de elementos intangibles específicos de la institución los cuales serán elegidos por cada Universidad atendiendo a sus propias características y entorno y a las demandas particulares de sus stakeholders.

En nuestra opinión, la creación de un marco de Informe de capital intelectual abierto, pero con algunas categorías homogéneas para asegurar la consistencia y comparación, puede permitir nuevas y atractivas posibilidades.

En concreto, el formato propuesto para dicho Informe de CI universitario constaría de dos partes distintas: (1) una parte esencialmente descriptiva, donde se presenta una descripción completa de la misión y de la visión de la institución, así como la formulación de los objetivos estratégicos de la Universidad en el área de los intangibles, y (2) una segunda parte correspondiente al nivel operacional, que está constituida por el conjunto de indicadores relativos a los recursos de capital intelectual de la Universidad (capital humano, capital estructural y capital relacional). En lo que respecta a los indicadores propuestos, se ha recogido una batería de treinta indicadores que son calificados de fundamentales o imprescindibles.

Nuestra propuesta de Informe de CI para las universidades españolas pretende servir de guía para ayudar a estas instituciones en el camino hacia la presentación de información útil a sus stakeholders, contribuyendo a una mayor transparencia y comparabilidad en el sector de la enseñanza superior.

Finalmente, algunos factores de éxito que las universidades han de tener en cuenta a la hora de elaborar sus Informes de CI son: (1) definir los objetivos estratégicos tan exactamente como sea posible, (2) discutir los objetivos corporativos y las estrategias, (3) no usar un modelo complicado, (4) formular los indicadores exacta y transparentemente, (5) intentar reducir la cantidad de indicadores a unos pocos, pero significativos, (6) iniciar un proceso de aprendizaje colectivo en la interpretación de los indicadores, (7) definir un equipo de proyecto con responsabilidades claras, (8) asegurar el compromiso de la alta dirección, (9) tener en cuenta la participación de los empleados y la comunicación de los beneficios del informe de CI, (10) iniciar un proceso de discusión en todos los niveles de la organización y con diferentes stakeholders externos, y (11) coordinar el proceso de implantación del informe de CI con otros informes de la institución, con el fin de evitar una sobrecarga de información, así como la duplicidad en la presentación de los datos. 


\section{REFERENCIAS BIBLIOGRÁFICAS}

ALTENBURGER, O.A. y SCHAFFHAUSER, Z.M. (2005). Intellectual capital reports for universities - a trial intellectual report at the University of Vienna, 1st Workshop on Visualising, Measuring and Managing Intangibles and Intellectual Capital, Ferrara (Italy).

AZOFRA, V., PRIETO, V. y SANTIDRIÁN, A. (2001). "Los indicadores de rendimiento y su contribución a la creación, medición y valoración del capital intelectual: estudio de un caso". Documentos de trabajo "Nuevas Tendencias en Dirección de Empresas", Universidad de Valladolid.

BEZHANI, I. (2010). "Intellectual capital reporting at UK universities" en Journal of Intellectual Capital, 11(2), pp. 179-207.

BODNÁR, V., HARANGOZÓ, T., TIRNITZ, T., RÉVÉSZ, E. y KOVÁTS, G. (2010). Managing intellectual capital in Hungarian Universities - the case of Corvinus University of Budapest, $2^{\text {nd }}$ European Conference on Intellectual Capital. ISCTE, Lisboa (Portugal).

BONTIS, N., DRAGONETTI, N.C., JACOBSEN, K. y ROOS, G. (1999). "The knowledge toolbox: A review of the Tools available to measure and manage intangible resources" en European Management Journal, 17(4), pp. 391-402.

BORDONABA, M.V., POLO, Y., y PALACIOS, L. (2006). "Valoración de los recursos intangibles: un análisis empírico para el sector de la franquicia" en Información Comercial Española, ICE: Revista de Economía, 829, pp. 177188.

BORNEMANN, M., KNAPP, A., SCHNEIDER, U. y SIXL, K.I. (1999). Holistic measurement of intellectual capital, International Symposium on Measuring and Reporting Intellectual Capital: Experience, Issues and Prospects, OCDE, Amsterdam (Holanda).

BROOKING, A. (1997). El capital intelectual. El principal activo de las empresas del tercer milenio. Barcelona: Ediciones Paidós Ibérica, S.A.

BUENO, E. (2002). "Dirección estratégica basada en conocimiento: Teoría y práctica de la nueva perspectiva", en Morcillo, P. y Fernández, J. (2002). Nuevas Claves para la Dirección Estratégica, Barcelona: Ed. Ariel.

BUENO, E. (Dir.) (2002). Indicadores de capital intelectual aplicados a la Actividad Investigadora y de Gestión en las Universidades y Centros Públicos de Investigación de la Comunidad de Madrid. En Capital Intelectual y Producción Científica. Madrid: Dirección General de Investigación, Consejería de Educación, Comunidad de Madrid.

BUENO, E. (Dir.) (2003). Gestión del conocimiento en Universidades y Organismos Públicos de Investigación. Madrid: Dirección General de Investigación, Consejería de Educación, Comunidad de Madrid.

BUENO, E.-CENTRO DE INVESTIGACIÓN SOBRE LA SOCIEDAD DEL CONOCIMIENTO (CIC) (2003). Modelo Intellectus: medición y gestión del capital 
intelectual. Documentos Intellectus $n^{\circ}$ 5. Madrid: Centro de Investigación sobre la Sociedad del Conocimiento.

BUENO, E., SALMADOR, M.P. y MERINO, C. (2008). "Génesis, concepto y desarrollo del capital intelectual en la economía del conocimiento: Una reflexión sobre el Modelo Intellectus y sus aplicaciones" en Estudios de Economía Aplicada, 26(2), pp. 43-64.

CAÑIBANO, L. y SÁNCHEZ, P. (2008). "Intellectual Capital Management and Reporting in Universities and Research Institutions" en Estudios de Economía Aplicada, 26(2), pp. 7-26.

CAÑIBANO, L., GISBERT, A., GARCÍA-MECA, E. y GARCÍA-OSMA, B. (2008). Los intangibles en la regulación contable. Madrid: Documento AECA \& Instituto Análisis Intangibles.

CAÑIBANO, L., SÁNCHEZ, P., GARCÍA-AYUSO, M. y CHAMINADE, C. (Eds) (2002). Directrices para la Gestión y Difusión de Información sobre Intangibles. Informe de Capital Intelectual. Proyecto Meritum. Madrid: Vodafone Fundación.

CASANUEVA, C. y GALLEGO, A. (2010). "Social capital and individual innovativeness in university research networks" en Innovation: management, policy \& practice, 12(1), pp. 105-117.

CONSEJO DE COORDINACIÓN UNIVERSITARIA (2010). Documento sobre Financiación de las Universidades. Madrid: Ministerio de Educación y Ciencia.

COY, D., TOWER, G. y DIXON, K. (2001). "Public accountability: A new paradigm for college and university annual reports" en Critical Perspective on Accounting, 12, pp. 1-31.

DANISH MINITRY OF SCIENCE, TECHNOLOGY AND INNOVATION (2000). A Guideline for Intellectual Capital Statements - A Key to Knowledge Management. Copenhagen: Danish Trade and Industry Development Council.

DE BOER, H., JONGHBLOED, B., BENNEWORTH, P., WESTERHEIJDEN, D. y FILE, J. (2012). Engaging in the modernisation Agenda for European Higher Education. Centre for Higher Education Policy Studies. European Centre for Strategic Management of Universities. University of Twente.

DELGADO, M., MARTÍN, G., NAVAS, J.E. y CRUZ, J. (2011). "Capital social, capital relacional e innovación tecnológica. Una aplicación al sector manufacturero español de alta y media-alta tecnología" en Cuadernos de Economía y Dirección de la Empresa, 14(4), pp. 207-211.

EDVINSSON, L. y MALONE, M. (1999). El capital intelectual. Cómo identificar y calcular el valor de los recursos intangibles de su empresa. Barcelona: Gestión 2000.

ELENA, S. (2007). Governing the University of the 21st Century: Intellectual Capital as a tool for strategic management. Lessons from the European experience. Tesis doctoral, Universidad Autónoma de Madrid.

ELECTRONICS AND TELECOMMUNICATIONS RESEARCH INSTITUTE (ETRI) (2005). Electronics and Telecommunications Research Instritute 
(ETRI) (2005): "Intellectual Capital Report". www.etri.er.kr. [Último acceso: Enero 2012]

EUROPEAN COMMISSION (2003). The role of the Universities in the Europe of Knowledge. Brussels 05/02/2003, COM (2003) 58 Final.

EUROPEAN COMMISSION (2006). Ricardis: Reporting intellectual capital to augment research, development and innovation in SMEs. Report to the Commission of the High Level Expert Group on Ricardis. http://ec.europa.eu/invest-in-research/pdf/download_en/20062977_web1.pdf [Último acceso: Enero 2012]

EUROPEAN COMMISSION (2010a). Feasibility study for creating a European University data collection. Final Study Report. EUMIDA Consortium.

EUROPEAN COMMISSION (2010b). A strategy for smart, sustainable and inclusive growth. Communicaton from the Commission Europe 2020. Brusells, 3.3.2010. COM(2010) 2020.

FAZLAGIC, A. (2005). "Measuring the intellectual capital of a University". Conference on Trends in the Management of Human Resources in Higher Education, Paris, OECD. http://www.oecd.org/dataoecd/56/16/35322785.pdf [Último acceso: Enero 2012]

FEDERAL MINISTRY OF EDUCATION, SCIENCE AND CULTURE (2002). University Organisation and Studies Act - University Act 2002 -, $\mathrm{N}^{\circ}$ 120/2002. http://www.bmbwk.gv.at. [Último acceso: Diciembre 2011]

FEDERAL MINISTRY OF EDUCATION, SCIENCE AND CULTURE (2006). Verordnung ueber die Wiessenbilanz (Wissensbilanz-Verordnung-WBV), BGB1, II Nr.63/2006. http://www.bmbwk.gv.at/universiteeten/recht/gesetze/ wbv/wbv.xml [Último acceso: Diciembre 2011]

GAETE, R.A. (2009). Participación de los stakeholders en la evaluación del comportamiento socialmente responsable de la gestión universitaria: perspectivas, obstáculos y propuestas. Congreso de la Asociación Española de Contabilidad y Administración de Empresas (AECA), Valladolid.

GONZÁLEZ, J.J. y RODRÍGUEZ, M.T. (2010). "Modelos de capital intelectual y sus indicadores en la universidad pública" en Cuadernos de Administración, 43, pp. 113-128.

GONZÁLEZ, O.J., FONTANEDA, I., CAMINO, M.A. y ANTÓN, A. (2010). La Responsabilidad Social en las Universidades Españolas 2010. Burgos: Universidad de Burgos.

GRAU, R.H. (2006). "Social, environmental and sustainability reporting and organizational value creation? Whose value? Whose creation?" en Accounting, Auditing and Accountability Journal, 19(6), pp. 793-819.

HAIR, J.F. (1999). Análisis Multivariante. Madrid: Prentice-Hall.

INSTITUTO DE CONTABILIDAD Y AUDITORÍA DE CUENTAS (ICAC) (2002). Informe sobre la situación actual de la contabilidad en España y líneas básicas para abordar su reforma (Libro Blanco para la reforma de la contabilidad en España). Madrid: ICAC. 
JONGBLOED, B., ENDERS, J. y SALERNO, C. (2008). "Higher education and its communities: Interconnections, interdependencies and a research agenda" en Higher Education, 56(3), pp. 303-324.

KAUFMANN, L. y SCHNEIDER, Y. (2004). "Intangibles. A synthesis of a current research" en Journal of Intellectual Capital, 5(3), pp. 366-388.

KEONG, K. (2008). "Intellectual capital: definitions, categorization and reporting models" en Journal of Intellectual Capital, 9(4), pp. 609-638.

LARRÁN, M. y BENAYAS, J. (2011). Indicadores de Responsabilidad Social Universitaria. III Jornadas Responsabilidad Social Universitaria, Zaragoza (España).

LARRÁN, M., LÓPEZ, A. y CALZADO, M.Y. (2010). Expectativas de los stakeholders en las Universidades públicas españolas: un estudio empírico. XIV Encuentro ASEPUC, A Coruña.

LEITNER, K.H. (2004). "Intellectual Capital reporting for universities: conceptual background and application for Austrian Universities" en Research Evaluation, 13(2), pp. 129-140.

LEV, B. (2003). Intangibles: Medición, Gestión e Información, Bilbao: Ediciones Deusto.

MÁRQUEZ, M. (2010). Medición del capital intelectual en las universidades. Modelo para el Subsistema de la Investigación Científica de la UAM. VIII Congreso Iberoamericano de Indicadores de Ciencia y Tecnología.

MARTíN, E. (2006). "La rendición de cuentas en las universidades públicas españolas: un análisis de la información revelada en los estados financieros" en Presupuesto y Gasto Público, 43, pp. 39-62.

MARTíN, E. y MONEVA, J.M. (2009). Análisis de la rendición de cuentas de las Universidades desde un enfoque de responsabilidad social. Workshop sobre Responsabilidad social, Gobierno corporativo y Transparencia informativa, Granada.

MELLE, M. (2007). "La responsabilidad social dentro del sector público" en Ekonomiaz, 65, pp. 84-107.

O'DWYER, B. (2005). "User needs in Sustainability Reporting: a perspective from stakeholders in Ireland" en European Accounting Review, 14(4).

OBSERVATORY OF EUROPEAN OF UNIVERSITY (OEU) (2006). "Methodological Guide", Final Report of the Observatory of the European University, PRIME Project. www.prime-noe.org. [Último acceso: Noviembre 2011]

OKUNOYE, A., FROLIC, M. y CRABLE, E. (2008). "Stakeholder influence and ERP implementation in higher education" en Journal of Information Technology Case and Application Research, 10(3), pp. 9-38.

ORTÍN, P., SALAS, V., TRUJILLO, M.V., y VENDRELL, F. (2007). El spin-off universitario en España como modelo de creación de empresas intensivas en tecnología. Madrid: Ministerio de Industria, Turismo y Comercio, Secretaría General de Industria, Dirección General de Política de la Pyme. 
RAMÍREZ, Y. (2010). "Análisis de las principales guías para la presentación de información sobre capital intelectual" en Estudios de Economía Aplicada, 28(2), pp. 481.

RAMÍREZ, Y. y BAIDEZ, A. (2011). "EI Balanced Scorecard como herramienta de gestión estratégica en las instituciones de educación superior" en Partida Doble, 232, pp. 64-76.

RAMÍREZ, Y., LORDUY, C. y ROJAS, J.A. (2007). "Intellectual capital management in Spanish Universities" en Journal of Intellectual Capital, 8(4), pp. 732-748.

RAMÍREZ, Y., SANTOS, J.F. y TEJADA, A. (2011). "Intellectual capital in Spanish public universities: stakeholders' information needs" en Journal of Intellectual Capital, 13(3), pp. 356-376.

ROOS, G. y ROOS, J. (1997). "Measuring your company's intellectual performance" en Long Range Planning, 30(3), pp. 413-426.

SALAS, V. (1996). "Economía y gestión de los activos intangibles" en Economía Industrial, 307, pp. 17-24.

SÁNCHEZ, P. y ELENA, E. (2007). "New management in higher education institutions: introducing intellectual capital approaches" en Conradi Research Review, 4(2), pp. 71-87.

SÁNCHEZ, P., ELENA, S. y CASTRILLO, R. (2006). "The Intellectual Capital Report of Universities. Guidelines for disclosing IC information". En Observatory of the European University: PRIME-OEU Methodological Guide, pp. 223-251.

SÁNCHEZ, P., ELENA, S. y CASTRILLO, R. (2009)."Intellectual capital dynamics in universities: a reporting model" en Journal of Intellectual Capital, 10(2), pp. 307-324.

SECRETARÍA DE ESTADO DE UNIVERSIDADES (2008). Estrategia Universidad 2015. Resumen ejecutivo. Madrid: Ministerio de Ciencia e Innovación.

SECUNDO, G., MARGHERITAM, A., ELIA, G. y PASSIANTE, G. (2010). "Intangible assets in higher education and research: mission, performance or both?" en Journal of Intellectual Capital, 11(2), pp. 140-157.

SCHAFFHAUSER, M. (2009). Intellectual capital reporting for Austrian Universities - a trilling work in progress. EIASM Workshop on the Process of Reform the University, Siena (Italia).

SILVESTRI, A. y VELTRI, S. (2011). "The intellectual capital report within universities: comparing experiences" en Economic Science Series, 20(2), pp. 618-624.

SIMÓ, P. y SALLÁN, J.M. (2008). "Capital intangible y capital intelectual: Revisión, definiciones y líneas de investigación" en Estudios de Economía Aplicada, 26(2), pp. 65-78.

WARDEN, C. (2003). Managing and Reporting Intellectual Capital: New Strategic Challenges for HEROs. IP Helpdesk Bulletin, 8. http://www.ipr-helpdesk.org/newsletter/8/pdf/EN/N08_EN.pdf [Último acceso: Diciembre 2011]. 